\title{
EDITORIAL
}

\section{Subspecialty training opportunities in radiology in India - The way forward}

\author{
Chander Mohan, SM
}

Director, Interventional Radiology, BLK Super Speciality Hospital, New Delhi, India. E-mail: brigcmohan@gmail.com

Dear colleagues,

As the incoming editor, I take this opportunity to thank the outgoing editor, Dr. Sanjay Jain and editorial board members for consolidating the hard work of previous office bearers of IJRI and raising the standards of the IJRI to such high levels. My team and I have an enormous task ahead of us; to maintain the high standards of professional excellence and passion that has come to characterize our journal.

Various advances in modern technology over the past few decades have rapidly transformed the practice of medicine and revolutionized the way imaging is practiced. The challenge for radiologists today is to keep pace with newer applications and expanding information; and also to match the high expectations of our clinical colleagues. Every radiologist should take efforts to maintain a high quality of work. Specializing in one or more regions of interest helps us meet this challenge and contribute more meaningfully to clinical medicine. Superspecialty institutions which have the expertise and state-of-the-art technology are able to rise up to this demand more easily. Teleradiology has ensured the availability of experts for interpretation even for imaging centers which do not possess in-house expertise. This has improved patient care in smaller cities and rural areas.

However, the organ system-based subspecialty training opportunities in radiology have not kept pace with the development of clinical subspecialties. We have many specialists in computed tomography scan and magnetic resonance imaging. However, there are only a few systembased specialists. This shortage of expertise has encouraged clinical colleagues to take up work that had hitherto been performed only by radiologists. The logistic difficulties for radiologists to provide adequate critical care and emergency support have also perhaps contributed to this situation. We are gradually losing various modalities to other clinical specialties. The only way for us to regain lost ground is to subspecialize in various systems to meet the exact requirements of interpretation with clinical relevance. Since opportunities for subspecialty radiology training are inadequate in our country, we should provide a reasonable exposure to subspecialty training during the radiology residency period. Further, institutions that have the expertise should provide accredited specialty-based fellowships. The next step forward would be restructuring of existing job opportunities to ensure a more even distribution of specialists across the country with the creation of specialtybased jobs even in smaller cities and mid-size private hospitals, besides tertiary care and academic institutions. The desirable scenario would be to have imaging departments that provide a constant level of basic, but further competent service in all subspecialties of radiology as it will result in better overall care. The expansion of "second-opinion" services from experts based on tertiary care hospitals through teleradiology can further aid in achieving this goal. The various subspecialty degree and fellowship programs under consideration by accrediting bodies will hopefully fulfill this much-needed requirement and create opportunities for radiologist to sub-specialize, thus maintaining the pride of place the specialty of radiology deserves.

The aim of the journal remains the same, to be the flagbearer and beacon of Indian radiology and be a presence to be reckoned with, in the international publishing scene. For this, we are dependent on our team of excellent reviewers and authors to send us their quality work and maintain quick turnaround times for decisions on manuscripts. We look forward to working closely with the new office bearers of IRIA as well as all the members of our great and honored association over the next few years as we strive to scale newer heights.

This is an open access article distributed under the terms of the Creative Commons Attribution-NonCommercial-ShareAlike 3.0 License, which allows others to remix, tweak, and build upon the work non-commercially, as long as the author is credited and the new creations are licensed under the identical terms.

\begin{tabular}{|l|l|}
\hline \multicolumn{2}{|c|}{ Access this article online } \\
\hline Quick Response Code: & Website: \\
& www.ijri.org \\
\hline
\end{tabular}

Cite this article as: Mohan C. Subspecialty training opportunities in radiology in India - The way forward. Indian J Radiol Imaging 2016;26:1. 